\title{
Cryoanalgesia in Interventional Pain Management
}

\author{
Andrea M. Trescot, MD
}

Cryoneuroablation, also known as cryoanalgesia or cryoneurolysis, is a specialized technique for providing long-term pain relief in interventional pain management settings. Modern cryoanalgesia traces its roots to Cooper et al who developed in 1961, a device that used liquid nitrogen in a hollow tube that was insulated at the tip and achieved a temperature of $-190^{\circ} \mathrm{C}$. Lloyd et al proposed that cryoanalgesia was superior to other methods of peripheral nerve destruction, including alcohol neurolysis, phenol neurolysis, or surgical lesions. The application of cold to tissues creates a conduction block, similar to the effect of local anesthetics. Long-term pain relief from nerve freezing occurs because ice crystals create vascular damage to the vasonervorum, which produces

Some say the world will end in fire, Some say in ice.

From what I've tasted of desire

I hold with those who favor fire. But if it had to perish twice,

I think I know enough of hate

To say that for destruction ice Is also great And would suffice.

-Robert Frost (1)

Cryoanalgesia, cryoneuroablation or cryoneurolysis is a specialized technique for providing long-term pain relief when pain has been shown to be caused by sensory nerves.

\section{HISTORY}

Man has known the use of cold for analgesia for thousands of years. Hippocrates (2) (460-377 BC) left us the first written records of the use of ice for pain relief, describing how snow was brought

From The Pain Center, Orange Park, Florida . Address Correspondence: Andrea M. Trescot, MD, The Pain Center, 1564 Kingsley Ave, Orange Park, FL 32073. E-mail: amt57@aol.com

Funding: There was no external funding in preparation of this manuscript. severe endoneural edema. Cryoanalgesia disrupts the nerve structure and creates wallerian degeneration, but leaves the myelin sheath and endoneurium intact.

Clinical applications of cryoanalgesia extend from its use in craniofacial pain secondary to trigeminal neuralgia, posterior auricular neuralgia, and glossopharyngeal neuralgia; chest wall pain with multiple conditions including post-thoracotomy neuromas, persistent pain after rib fractures, and post herpetic neuralgia in thoracic distribution; abdominal and pelvic pain secondary to ilioinguinal, iliohypogastric, genitofemoral, subgastric neuralgia; pudendal neuralgia; low back pain and lower extremity pain secondary to lumbar facet joint pathology,

down from the mountains in ancient Greece and applied to wounds for pain relief. The ancient Egyptians documented the use of low temperature for analgesia (3). Avicenna of Persia (980-1070 AD) an early physician, described the use of cold for pre-operative analgesia (4). Jean Larre', Napoleon's Surgeon General, noted in 1812 that half-frozen soldiers in the Moscow battle were able to tolerate limb amputation with little or no pain (5). In addition, John Hunter (6) noted in 1777 that when roster comb cells were killed by cold, the base of the comb healed without scarring. Arnott (7) described the use of severe cold to treat pain in 1848 , and by 1851 , he was avidly promoted the application of cold to relieve certain types of cancer and nerve pain, using mixtures of ice and salt at $-20^{\circ} \mathrm{C}(8)$. He also noted the hemostatic and anesthetic effects of such a mixture. Richardson (9) introduced ether spray in 1866 for topical anesthesia, which was followed by ethyl chloride spray in 1891. Thus "to freeze" became synonymous with "to numb". Trendelenberg (10) in 1917 demonstrated that freezing tissues caused severe nerve damage and loss of function but noted that the nerves regen- pseudosciatica, pain involving intraspinous ligament or supragluteal nerve, sacroiliac joint pain, cluneal neuralgia, obturator neuritis, and various types of peripheral neuropathy; and upper extremity pain secondary to suprascapular neuritis and other conditions of peripheral neuritis.

This review describes historical concepts, physics and equipment, various clinical aspects, along with technical features, indications and contraindications, with clinical description of multiple conditions amenable to cryoanalgesia in interventional pain management settings.

Keywords: Cryoanalgesia, cryoneurolysis, cryoneuroablation, sensory nerves, interventional pain management

erated without neuroma formation.

Modern cryoanalgesia traces its roots to Cooper et al (11) who developed in 1961 a device that used liquid nitrogen in a hollow tube that was insulated at the tip and achieved a temperature of $-190^{\circ} \mathrm{C}$. Amoils, an ophthalmic surgeon, developed a simpler hand held device in 1967 (12), which used carbon dioxide or nitrous oxide and could achieve temperatures of $-70^{\circ} \mathrm{C}$. Lloyd et al (13) coined the term "cryoanalgesia" for its use in pain management. He proposed that this technique was superior to other methods of peripheral nerve destruction, e.g. alcohol, phenol, or surgical lesions, because it is not followed by neuritis or neuralgia (14). Current probes range in size from 1.4 to 2 millimeters in size. Most have a built in nerve stimulator for localization of the nerve and a thermistor to identify temperature at the tip. Barnard, Lloyd, Evans, Green, and Glynn (15-17) popularized cryoneuroablation in the early 1980 's, but relatively little has been written on the technique since. This article is an attempt to gather the information on the current use of cryoneuroablation. 


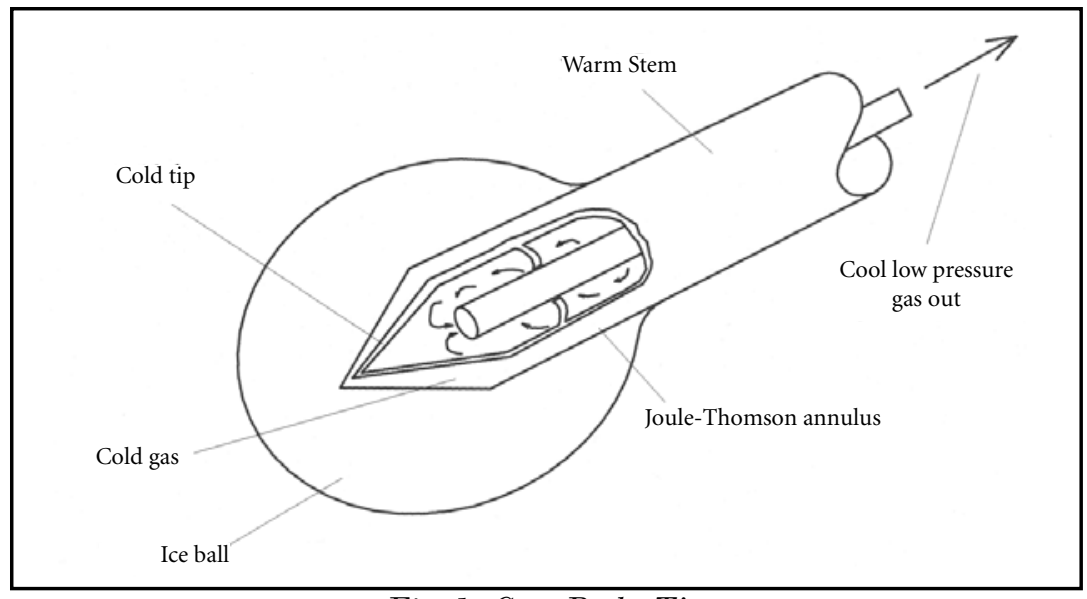

Fig. 1. Cryo Probe Tip

oneuroablation, with a release of sequestered proteins that may trigger an autoimmune response to the targeted to the lesioned tissues, which might explain the prolonged effect (22-24).

The extent of the freezing (and subsequent nerve damage) is a function of 1) the proximity of the probe to the nerve, 2) the size of the cryoprobe, 3 ) the size of the ice ball formed, 4) the completeness of the freezing (rate and duration), and 5) the temperature of the tissues in proximity to the probe which is affected by local heat sinks (such as CSF/blood flow). The intensity and duration of analgesia is dependent on the degree of nerve damage from the ice ball (25). For example, exposure of the fingers or toes to winter cold can lead to numbness (which is reversible) up to frostbite (which may result in permanent changes). The use of the nerve stimulator, meticulous localization of the nerve, the use of the largest probe appropriate, and the use of appropriate freeze and defrost cycles will increase degree of nerve disruption and therefore the success rate. Repeat cycles decrease the temperature at sites further from the probe, increasing the size of the ice ball formed and increasing the length of nerve incorporated into the ice ball. The use of saline with epinephrine in proximity to the intended nerve may decrease the "heat sink" of the nearby warm blood flow and at the same time potentially decrease bruising from the placement of the probe which would be expected to decrease post procedure soreness. The cryoprobe should typically be withdrawn only after the ice ball has thawed since trying to withdraw the probe with the ice ball present could tear the attached tissues and avulse a nerve segment.

Current probes range in size from 1.4 to 2 millimeters in size. Most have a built in nerve stimulator for localization of the nerve and a thermistor to identify temperature at the tip. The nerve stimulator allows a frequency choice for sensory $(100 \mathrm{~Hz})$ or motor $(2 \mathrm{~Hz})$ responses. Use of an introducer is recommended because the introducer can be used to infiltrate local anesthetic, isolate the electrical current from stimulation to just the tip of the probe (should the Teflon coating fail over time), and afford skin protection from the ice ball during treatment of superficial structures. The most commonly used introducer is a large gauge IV catheter. The sharp tip pierces the tissues more easily 
than the probe itself, and the stylet can be removed to allow introduction of the probe. A 12-gauge catheter is used for the $2.0 \mathrm{~mm}$ probe and a 14 or 16 gauge catheter is used for the $1.4 \mathrm{~mm}$ probe.

\section{Clinical ASPECTS}

"You can not treat what you can not diagnose," is the tenet of the effective interventional pain management specialist. The cryoneurolysis technique is only as good as the diagnostic technique that precedes it. It is critical that a precise diagnosis be made prior to an attempt to freeze any nerve. In fact, the first step is to confirm that pathology is primarily isolated to sensory nerves. Performing a meticulous diagnostic block, using small volumes of local anesthetic no greater than the volume of the freeze that would be created $(0.2$ to $0.8 \mathrm{~mL})$ does this. Use of a nerve stimulator as well as fluoroscopic guidance, direct exposure, or absolute anatomic location of the structure is critical. Because the nerve is expected to regrow, it is also critical that the period of pain relief after the cryoneuroablation be used to recreate as normal environment as possible so that as the nerve regenerates the original pathology (entrapment) does not recur. There is no evidence of permanent neurologic damage as a result of multiple cryoneuroablation procedures (26). Success of cryoanalgesia is directly related to patient selection, accurate probe placement and the post procedure rehabilitation process.

\section{Patient Preparation}

Informed consent is as important for this technique as it is for any other intervention. Risk, complications, and specific contraindications should be discussed and that discussion documented. The machine and gas supply should be checked, and the cryoprobe purged of the room air gases. The patient is placed in the appropriate position, and the nerve location confirmed by palpation, and when appropriate, by fluoroscopic localization. Minimal, if any, sedation should be used, since it is critical that the patient be awake enough to respond to the stimulation.

\section{Technique}

The technique requires precise localization of the target nerve. Depending on the anatomy and ease of locating landmarks, cryoneuroablation can be done with or without fluoroscopy. After a sterile prep and drape, a small amount of local anesthetic is infiltrated subcutaneously. A 27-gauge 1 1/2-inch needle is then advanced into the subcutaneous tissues, and $1 \mathrm{~mL}$ of saline with freshly added epinephrine 1:200,000 is infiltrated for hemostasis. A small incision is made in the skin, and an IV introducer is then advanced to the target area. Small doses of additional local anesthetic can be injected through the introducer, as it is advanced, taking care not to anesthetize the actual target area.

When the introducer comes in contact with the target area, the stylet is removed and the cryo probe is then advanced through the catheter and the tip of the probe exposed by withdrawing the catheter into the subcutaneous tissues. Most of the techniques described here use bone as the "backstop", allowing the nerve to be "pinned" against the bone to facilitate precise nerve contact with the probe. Not all catheters are created equally. It is important, especially when changing brands, to confirm that the probe will fit through the catheter prior to introducing the catheter through the skin. There is little worse than getting the catheter placed perfectly, only to be unable to advance the probe through the catheter.

Accurate and meticulous sensory stimulation is critical for success. As the probe moves across the periosteum, sensory stimulation $(100-\mathrm{Hz})$, first at 2 volts, and then as low as 0.5 volts is used to identify the nerve. Particular care must be used in the movement of the probe, since the movement itself may cause a paresthesia that is not an actual sensory stimulation but rather a "piezoelectric" or traction effect. As soon as the patient perceives stimulation in, or paresthesia to the area of maximal pain, the stimulation should be immediately turned to zero to avoid over-stimulation of the nerve. Turning the stimulator back on its previous setting should again provide stimulation without movement of the probe, confirming the actual stimulation of the nerve. The procedure is repeated with progressively decreasing voltage, until stimulation can be reliably obtained at 0.5 volts. At this time, motor stimulation $(2-\mathrm{Hz})$ is used at its highest voltage to confirm that the probe is not too close to nearby motor nerves. Gas flows are then turned up to ten to twelve liters per minute (for the $2.0 \mathrm{~mm}$ probe) or eight to ten liters per minute (for the $1.4 \mathrm{~mm}$ probe) and a series of two to three minute freezes with thirty seconds defrosting between each cycle is performed. There is usually a burning pain on initiation of the first freeze cycle which often replicates the pain and should resolved within approximately 30 seconds. The rest of the procedure should be completely painless.

Freeze cycles of three minutes result in optimal density of the ice ball. It is clear that freeze cycles longer than three minutes do not result in any additional benefit, since the ice acts as its own insulation. Adequate thawing (more than 20 seconds but less than 40 seconds) allows subsequent freezes to increase the size of the freeze zone. After the last defrost cycle, the probe is withdrawn from the catheter and $1 \mathrm{~mL}$ of $0.5 \%$ bupivacaine is used to infiltrate the tissues as the catheter is withdrawn. This provides postprocedure analgesia.

It is critical that minimal sedation be used for the procedure, allowing the patient to interact fully with the determination of sensory stimulation. Done with a gentle technique, this should not be a painful procedure, and it is common for me to do these in my office with no sedation at all. Small doses of a short acting narcotic (50-100 mg of fentanyl) should be more than adequate for analgesia.

\section{Alternatives}

There are few options other than cryoneuroablation for the ablation of large sensory nerves. Surgical resection has been used but is all too often associated with postoperative neuroma formation, and one of the clinical uses for cryoneuroablation is the treatment of postoperative neuromas. Alcohol and phenol will destroy the nerve but are also associated with neuroma formation. Narcotics do not treat nerve pain but rather only "mask" the pain. Anticonvulsants should be used before attempting cryoablation. Pulse radiofrequency lesioning has recently been used. The theoretic advantage would be the use of smaller (22gauge) probes. However, long-term results are not available, and the mechanism is not yet elucidated.

\section{Contraindications}

General contraindications to percutaneous cryoneurolysis are quite basic: bleeding diathesis, infection (local or systemic), and an uninformed patient. 
The bleeding contraindication is relative, and is important primarily in those situations where bleeding could go unnoticed, such as an intercostal cryoneurolysis with bleeding into the thorax or an obturator nerve cryoneurolysis where there could be hidden bleeding into the pelvis. Placing the probe through infected tissue could seed the infection into deeper tissues. Patients must be warned of the risks of depigmentation or hyperpigmentation at the cryolesion site, and the diagnostic block should be used to let the patients "preview" the effect, stressing that the lesion creates numbness and not just pain relief. Some patients have actually felt distressed by the numbing effect, for instance complaining about numbness when brushing their hair after an occipital cryolesion. Alopecia may also occur at the cryo site, especially at the eyebrow when performing a supraorbital cryolesion. There is only on reported case of neuritis after cryoneuroablation (27). With a well-informed patient, outcomes will be improved and the patient's expectations more likely to be met.

\section{Clinical Applications in Craniofacial Pain}

\section{Trigeminal Nerve and Branches Supraorbital Neuralgia}

The supraorbital nerve is the termination of the first division of the trigeminal nerve. Irritation of the nerve occurs primarily at the supraorbital notch. A small ligament completes the inferior border of a foramen through which the nerve passes prior to passage through the orbicularis oculi.

Commonly confused with migraine and frontal sinusitis, the pain of supraorbital neuralgia most typically manifests as frontal headache often associated with blurred vision, nausea and photophobia. Vulnerable to blunt trauma, this nerve can be injured by deceleration against an automobile windshield or through pugilistic blows. This neuralgia tends to worsen with time following the trauma as the injured tissue slowly develops a cicatrix which eventually envelopes the nerve. Spasm of the orbicularis oculi (such as frowning or squinting) exacerbates the entrapment. This etiology is supported by the efficacy of botulism toxin in the forehead region in the treatment of "migraines". However, the botulism relief is only expected to last $2-3$ months, where the cryoneuroablation relief can be for up to a year. Less commonly, the nerve can be injured as the result of acute herpetic infection (e.g. shingles), Paget's disease, and neoplasm. Patients will often experience an increase in headache intensity and frequency with menstruation (associated with fluid retention), salt intake, stress and bright light or vision changes (which causes squinting).

\section{Technique}

Cryoneuroablation of the supraorbital nerve can be accomplished via an open operative technique involving dissection under local anesthesia. The nerve can then be frozen under direct vision. The closed technique involves using the $1.4 \mathrm{~mm}$ probe, passed via a 14-gauge intravenous catheter introducer. Two or three 2-minute cycles usually are sufficient. The supratrochlear nerve, located at the medial aspect of the orbit, may also be involved and is lesioned in a similar manner. In this cosmetically important area, particular care must be used to avoid thermal damage to the sensitive skin around the eye. Entry of the catheter and probe should be below or above the eyebrow line. This avoids damage to the brow follicles, with subsequent alopecia. Changes in skin color can be expected, but generally resolve in a matter of months; however, the patient must be counseled appropriately.

\section{Infraorbital Neuralgia}

The infraorbital nerve is the termination of the second division of the trigeminal nerve. Irritative peripheral neuropathy occurs principally at the infraorbital foramen. Also vulnerable to blunt trauma, this nerve is often injured by pugilistic blows. This neuralgia tends to worsen with time following the trauma as the injured tissues slowly develop cicatrix that entraps the nerve. This nerve can also be injured as the result of fracture of the zygoma, with entrapment of the nerve from the formation of bony callus. Commonly confused with maxillary sinusitis, the pain of infraorbital neuralgia typically presents as maxillary pain worsened by smiling and laughter (which put tension on the zygomaticus musculatures). Because of referred pain to the teeth, patients often undergo futile dental procedures prior to presentation. As with the aforementioned entrapments, these patients will often experience an increase in headache intensity and frequency with menstruation, salt intake, stress and bright light.

\section{Technique}

Cryoneuroablation of the infraorbital nerve can be accomplished via an open operative technique involving dissection under local anesthesia, and the nerve can be thereby frozen under direct vision. The closed technique involves using the 1.4 $\mathrm{mm}$ probe, passed via a 14-gauge introducer, as close as possible to the foremen. This can be accomplished by a direct percutaneous approach but this area is also cosmetically important, so to minimize cosmetic damage, the intraoral approach can be employed. The 12-gauge introducer and $2.0 \mathrm{~mm}$ probe are inserted through the superior buccal-labial fold. The probe is then advanced until it lies over the infraorbital foramen. Two or three 2-minute cycle seem to be sufficient.

\section{Mandibular Neuralgia}

The mandibular nerve derives from the third division of the trigeminal nerve. This nerve can be injured or irritated at many locations along its path. It is most commonly injured as the result of muscular hypertrophy of the pterygoids, which results from chronic bruxism. It may also be injured as the result of loss of vertical dimension of oral cavity, i.e., loss of posterior dentition resulting in dysfunctional dental occlusion and subsequent pressure on the mandibular nerve as it passes through the pterygoid fossa. Often associated with referred pain to the teeth, patients may undergo extensive and futile dental procedures prior to presentation. Multiple extractions and endodontic procedures are commonly observed and serve to make the entrapment worse.

\section{Technique}

Cryoneuroablation of the mandibular nerve can be accomplished using an open or closed technique. In the closed approach, the patient is placed in the semi recumbent position and the jaw is opened 3-5 mm, allowing the coronoid process of the mandible to rotate rostrally. An inverted equilateral triangle can be imagined with the base of this triangle being formed by the coronoid process, the one segment of the triangle being formed by the neck of the mandible, and the last segment of the triangle being formed by the coronoid process of the mandible. After injecting a small amount of local anes- 
thetic in the skin and subcutaneous tissues, a 27-gauge needle is passed in the center of this triangle until a second "pop" is felt as the needle enters the fascial plane between the temporalis and the lateral pterygoid muscles. Saline containing epinephrine 1:200,000 is injected in the area to minimize bruising. Notation is made as to the depth of the needle, and the needle is withdrawn. A 14-gauge intravenous catheter is then placed to this depth, and a $1.4 \mathrm{~mm}$ cryoprobe is advanced using a peripheral nerve stimulator. After location of the nerve, a three-minute cryo-cycle followed by 2-two minute cycles is generally sufficient. There is a high probability of lateral tongue numbness post procedure, since this cryoablation technique would be expected to include the lingular nerve, and patients should be counseled accordingly. A similar approach to the maxillary nerve can be used, angling the probe anteriorly and using the sensory nerve stimulator. As an alternative, because of cosmetic considerations, an intraoral approach can be used, locating the mandibular nerve at the medial superior border of the lingular mandible. With care, the lingular nerve is often spared and may therefore be a preferable approach.

\section{Mental Neuralgia}

The mental nerve is the termination of the third division of the trigeminal nerve. Irritative peripheral neuropathy occurs principally at the mental foramen. Less vulnerable to blunt trauma, this nerve is most often injured by as the result of bony impingement following changes in mandibular bone architecture. Occurring chiefly in elderly edentulous patients, the pain of mental neuralgia most typically manifests as pain in the chin, lower lip and gum line.

\section{Technique}

The closed cryoneuroablative technique for the mental nerve involves using the $1.4 \mathrm{~mm}$ probe passed via a 14-gauge introducer, percutaneously or intraorally. Two or three 2-minute cycles seem to be sufficient. Insofar as this area is also cosmetically important, the considerations mentioned above should be entertained for this area as well.

\section{Auriculotemporal Neuralgia}

The auriculotemporal nerve derives from the third division of the trigeminal nerve. Irritative peripheral neuropa- thy occurs principally at two sites along the course of this nerve. The most common site of entrapment is immediately proximal to the parietal ridge at the attachment of the temporalis musculature. Less commonly, the nerve can be injured posterior to the ramus of the mandible. This can be triggered by clenching or bruxism. Clinical presentation of the auriculotemporal pathology consists of temporal pain associated with retro orbital pain. Referred pain to the teeth is often seen. The patient often awakens at night or in the early morning with temporal headache. The pain is described as throbbing, aching and pounding, and the pain can be unilateral or bilateral. Because it is associated with blurry vision, nausea and emesis, this headache is mistaken for vascular "migraines". Most commonly associated with cross bite, bruxism, and functional abnormality of the temporomandibular joint, this syndrome also associated with malformation or dysmorphia of the mandible or maxilla. Patients will often experience an increase in headache intensity and frequency with menstruation, salt intake, stress, or trauma (to include dental work).

\section{Technique}

To locate the auriculotemporal nerve distally, the base of an equilateral triangle is imagined between the corner of the eye and the anterior tragus. The apex of the triangle locates the parietal attachment of the temporalis musculature and the distal site of entrapment of the auriculotemporal nerve. A 12-gauge intravenous catheter is used as the introducer for the 2.0 $\mathrm{mm}$ cryoprobe. The proximal entrapment occurs just in front of the TMJ as the nerve curves in front of the joint. Particular care must be taken to avoid the facial nerve, which exits at this level. The 14 -gauge catheter is used with the $1.4 \mathrm{~mm}$ probe so as to limit possible trauma to the facial nerve.

\section{Trigeminal Neuralgia}

It is not usually necessary to destroy the trigeminal nerve itself, since pathology is mostly confined to individual branches. However, occasionally the entire nerve needs neuroablation. Tic douloureux pain that does not have a distal trigger zone may respond to lesioning of the nerve as it leaves the cranium.

\section{Technique}

Using fluoroscopy with the patient supine and neck extended, the foramen ovale is identified, and a 27 -gauge needle is used to infiltrate the region with saline containing epinephrine $1: 200,000$ to minimize bruising. The $1.4 \mathrm{~mm}$ probe is advanced through a 14 gauge intravenous catheter that has been positioned under fluoroscopy, and, using sensory stimulation, the area of maximal stimulation identified. With care, the ophthalmic portion of the trigeminal nerve can sometimes be avoided, but clearly the patient needs to be warned regarding the risks of hypoesthesia of the eye with this technique, which obviously limits this approach.

\section{Posterior Auricular Neuralgia}

Posterior auricular neuralgia is often seen weeks to years after blunt injury to the mastoid area. Seen commonly in physically abused women, the left side is most often involved due to the preponderance of right-handed spouse abusers. The clinical presentation consists of pain in the ear, along with a feeling of "fullness" and tenderness. This syndrome is often misdiagnosed as a chronic ear infection, and again is often worse with menstruation and salt intake. The nerve may also be entrapped by the sternocleidomastoid (SCM) muscle. Trigger point treatment may be adequate for most patients but some will need more aggressive treatment such as cryoablation. Klein et al (28) described the treatment of "cryptogenic earache" with posterior auricular nerve blocks.

\section{Technique}

The posterior auricular nerve runs along the posterior border of the sternocleidomastoid musculature, superficially and immediately posterior to the mastoid. A 12-gauge intravenous catheter is used as the introducer for the $2.0 \mathrm{~mm}$ cryoprobe, taking care to protect the thin skin in this area.

\section{Glossopharyngeal Neuralgia}

The glossopharyngeal nerve exits the skull with the vagus and spinal accessory nerves through the jugular foramen, descends anterior to the carotid artery and deep to the styloid, and then turns to the tongue where it passes through the tonsillar fossa. Both a motor and sensory nerve, it provides sensation to the middle ear, the posterior third of the tongue, the palatine tonsils, and the pharynx. Although 
the glossopharyngeal nerve block is primarily used as an anesthesia block for intubations, cryoneuroablation may be appropriate for postoperative pain relief for tonsillectomies as well as for cancer related throat and neck pain, or to break the reflex cycle of intractable hiccups (29).

\section{Technique}

Cryoneuroablation at the styloid process is not recommended, since the carotid artery is directly behind the target, and a 12-gauge hole in the carotid from the introducer would be difficult to manage. In addition, the vagus and spinal accessory nerve also pass through this area, and it would be difficult to avoid lysis of these nerves as well. As a result, the usual site for cryoneuroablation is at the tonsillar fossa. The patient is placed supine and the tongue retracted medially. The nerve is located at the inferior portion of the tonsillar pillar. The mucosa is anesthetized with a topical spray or pledget, and $1 \mathrm{~mL}$ of saline with epinephrine is infiltrated for hemostasis, looking as well for intravascular response to the epinephrine. The 12-gauge introducer is then advanced subcutaneously, and the $2 \mathrm{~mm}$ probe advanced through the catheter. Sensory stimulation should refer to the ear and throat, and there may be a throat motor stimulation. Care must be used to avoid the palatine artery. This may be done most easily at surgical tonsillectomy, when the nerve is exposed.

\section{Clinical Effectiveness}

Intractable face pain from a variety of causes may be treatable with cryoneuroablation. Bernard, Lloyd and Glynn (30) reported on 21 patients with intractable face pain, unresponsive to medical and surgical management. They diagnosed pain secondary to entrapments of several nerves, including the supraorbital, infraorbital, mental, and lingular nerves. All the nerves were treated with open (or exposed) cryoneuroablation. Barnard, Lloyd, and Evans (31) reported on 54 patients with chronic facial pain. Patients were selected for cryoneuroablation after they had a temporary response to local anesthetic injections. The mean duration of sensory loss was 60 (5117) days. The success of the blockade appeared to be an "all or nothing" effect, i.e., the patients with only with 5 day duration of pain relief reflected the failure to adequately freeze the nerve. They emphasized the difference between nerve "killing" and simple nerve "cooling". Diagnoses included non-herpetic neuralgia, tic douloureux, post surgical neuralgia, atypical facial neuralgia, and post herpetic neuralgia. $30-40 \%$ of the patients other than the PHN patients had relief for more than 6 months. No PHN patients had relief for greater than 1 year; however the other groups had more than a year's relief in 17$20 \%$ of the cases.

Trigeminal neuralgia or tic douloureux has caused debilitating pain in a group of very unfortunate patients. The advances in anticonvulsant therapy have helped, but the lancinating pain that may occur spontaneously or with the lightest touch of a "trigger zone" can be extremely debilitating. Nally et al (32) looked at 112 patients with paroxysmal trigeminal neuralgia. Intraoral or periorbital dissections of the peripheral branches of the trigeminal were performed. These included the supraorbital, supratrochlear, infraorbital, mental, posterior and middle superior dental, greater palatine, lingular, and long buccal nerves. An average of 2.2 procedures per patient over a 5-year period were reported. As an example, $68 \%$ of the 78 mental nerves treated remained pain free over 52 months. Similar results were seen with the other nerves, and patients noted that if and when the pain returned, it was at a lower pain level. Several patients noted that when the pain returned it was to a different site, but freezing the new site would also provide relief. Nally (33) also looked at 211 patients over a 22year period and concluded that cryotherapy offered significant long-term relief.

In 1988, Zakrzewska (34) initially reported a six-year experience with cryoanalgesia in the treatment of paroxysmal trigeminal neuralgia. Then in 1991 (35), he further reviewed 475 trigeminal neuralgia patients followed over a ten-year period. One hundred forty five of those patients underwent cryotherapy, 265 underwent radiofrequency thermocoagulation, and 65 underwent microvascular decompression. Mean follow up was 45 months in each group. Morbidity after cryotherapy was low, whereas radiofrequency thermocoagulation resulted in more prolonged sensory loss $(88 \%)$, anesthesia dolorosa $(8 \%)$, and eye problems (15\%). Microvascular decompression was associated with eighth cranial nerve problems in $11 \%$ of the patients and a $1 \%$ mortality rate. None of the cryoneuroablation patients developed anesthesia dolorosa. Of the patients treated with RF, 75\% continued to have sensory loss. In the cryoablation patients, the area of sensory loss was small but in the RF patients it sometimes extended across all three divisions of the trigeminal nerve, and $62 \%$ of these patients felt the sensory loss affected their life.

One of the most commonly preformed surgical procedures is a tonsillectomy, and pain management has been a significant problem. Postoperative tonsillectomy pain is thought to be due to a combination of nerve irritation, inflammation, and pharyngeal muscle spasms. In a prospective, randomized, doubleblinded study of 59 patients, Robinson and Purdie (36) reported on patients undergoing bilateral tonsillectomies. The patients were randomized to cryoneuroablation of the glossopharyngeal nerve or a control group. The cryoprobe was inserted superficially into the tonsillar fossa. Treatment resulted in a reduction of pain for ten days and a faster return to work or school compared to controls.

\section{Clinical Applications in Chest Wall Pain}

Of all the post-operative indications for cryoneurolysis, lesioning of the intercostal nerve intraoperatively has been the most extensively studied. The nerve is very easily identified at thoracotomy, and intraoperative cryoneuroablation can provide significant and long lasting postoperative analgesia. It is somewhat more difficult to address post-thoracotomy neuromas, persistent pain after rib fractures, or thoracic post herpetic neuralgia, but a percutaneous technique can provide excellent analgesia.

\section{Technique}

In the open technique, after the thoracotomy is complete, the cryoprobe is placed directly on the nerve at the posterior rib angle. The nerve is easily visualized beneath the parietal pleura. Because each rib has an innervation contribution from the rib below and the rib above, it is advisable to lesion the intercostal nerves above and below the incision line as well. Because the nerves are exposed, one or two freeze cycles should be adequate.

With the percutaneous approach, the technique has to take into consideration the underlying lung and the intercostal artery, which acts as a heat sink. Physicians are traditionally taught to perform intercostal nerve blocks by advancing the 
needle perpendicular to the inferior edge of rib and then "walking it off the edge of the bone", dropping to just before the parietal pleura. However, the nerve is actually up under the curve of the rib. In addition, the intercostal artery acts as a huge "heat sink", limiting the size of the ice ball and therefore the effectiveness of the cryolesion. By introducing the probe perpendicular to the nerve, the area of freezing is limited, which also limits the effectiveness of the cryolesion. In addition, the temptation is to use a smaller probe because of the concern regarding advancing a 12-gauge needle into the pleural space, causing a pneumothorax. The technique I recommend somewhat different. I recommend approaching the rib edge tangentially from anterior to posterior, then pushing the tip of the probe up under the edge of the rib. This accomplishes several things. It dramatically reduces the risk of pneumothorax, and it increases the length of contact of the probe on the nerve, increasing the effectiveness of the cryolesion. It is important to use the largest probe possible to overcome the arterial heat sink.

\section{Clinical Effectiveness}

Nelson (37) first described intraoperative intercostal cryoneurolysis in 1974. The technique is most effective in relieving incisional pain, and provides relatively little relief of visceral pleuritic pain or the pain of ligamentous or muscle pains. It provides no relief for chest tube pain. The multiple pain generators involved in post thoracotomy pain make cryoneuroablation difficult to use as a sole treatment. Despite these limitations, studies have shown that patients have less postoperative pain and less opioid requirement, both in the immediate postoperative period and in the weeks following the procedure (38). Orr et al (39) studied 45 patients randomized into 3 groups: a control group that received IM morphine postoperatively, a cryoanalgesia group, and a morphine infusion group. All patients underwent a general anesthetic, and, while the chest was open, the control and infusion groups had rib blocks performed with $0.5 \%$ bupivacaine while the cryoanalgesia group underwent a sharp dissection of the nerves followed by a 45 second freeze cycle under direct vision. The number of requests for analgesics was less for the cryoanalgesia group than for the controls, and the morphine infu- sion and control groups used the same total dose of morphine. The authors noted that the cryoneuroablation added about 10 minutes time to the procedure but gave better postoperative pain relief. This same group of investigators (40) did a further study comparing the original patients to an additional group of patients that included 23 patients who received the cryoneuroablation as well as a continuous infusion of morphine. Pain relief was best in the cryo-plus-infusion group, and at eight days postoperatively the cryoanalgesia patients had the best pain relief at rest (though there was no significant difference in pain with movement). Although a morphine infusion gave good relief and required very little special equipment or expertise, the authors felt that cryoneuroablation of the intercostals nerves at the time of surgery gave enough extra relief to be worth the extra 10 minutes of surgical time. It must be noted that cryoanalgesia of the $3^{\text {rd }}$ and $4^{\text {th }}$ intercostals can cause ipsilateral nipple anesthesia. Riopelle (41) suggested using a lower incision and not freezing nerves above the $5^{\text {th }}$ intercostals nerve. Denervation of the intercostals nerves appears to have no consequence, but loss of tone from the external and internal oblique muscles can cause a subtle but definite subcostal bulge that resolves with the return of sensation (42). There has been one case report of a neuroma formation after the use of cryoneuroablation for post thoracotomy pain (43), and several patients who have noted sensory deficits for up to six months. Comparative studies suggest superior relief with epidural analgesia (44), and the time necessary to perform lesions at multiple levels limit the usefulness of the technique. However, with the elimination of reimbursement for preoperative epidurals, the need for continuous monitoring during the epidural infusion, and the weeks of postoperative relief available with cryoneuroablation, thoracic surgeons may be interested in resurrecting the technique.

It is the experience with post-thoracotomy pain and cryoneuroablation that leads to its use in other chronic chest wall pains. The postoperative neuroma, costochondritis, post herpetic neuralgia, and rib fractures have all been treated with cryoneuroablation. Two large series suggest improved pain relief and few complications. Green et al (45) studied the effectiveness of cryoanalgesia on 43 patients with post herpetic neuralgia or intercos- tal neuralgia. Fifty percent of the patients noted significant relief of 3 month's duration. No patients developed neuritis, and the pain relief outlasted the return of sensory function. Another study of 70 patients with chest wall pain of a variety of etiologies noted pain relief from cryoanalgesia lasting one week to 12 months, with the post herpetic neuralgia patients uniformly noting a poorer response (46).

\section{Clinical Applications in Abdominal} And Pelvic Pain

\section{Ilioinguinal, Iliohypogastric, Genitofemoral, Subgastric Neuralgia}

Arising from the anterior primary ramus of the first lumbar nerve root via the lumbar plexus, the ilioinguinal nerve pierces the internal oblique muscle mediocaudally to the anterior superior iliac spine and then passes through the inguinal canal and accompanies the spermatic cord through the superficial inguinal ring to supply of the thigh and scrotum or labia (41). This nerve is often injured at lateral border of the rectus sheath, approximately $5 \mathrm{~cm}$ from midline, $10 \mathrm{cms}$ inferior to the umbilicus where it perforates the superior crus of the superficial inguinal ring. The ilioinguinal nerve may be injured during inguinal herniorrhaphy, and as the result of compression from the bladder retractor during abdominal surgery, particularly when the Pfannenstiel incision is employed. Even midline incisions may be associated with entrapment of the nerves, often months or years later as the scar cicatrix contracts. Occasionally this nerve is injured by tight fitting garments, e.g., belts and weapons holsters. The iliohypogastric nerve pathology will present in a similar manner but this nerve entrapment occurs about two fingerbreadths higher. There may be a communication between these two nerves, and their sizes are inversely related. Both can be traumatized by the expanding abdomen of late pregnancy or ascites. Both can mimic appendicitis (on the right) or diverticulitis (on the left). The fluid retentions associated with the perimenstrual time frame can also result in entrapment of the nerves and subsequent "endometriosis" pain.

The genitofemoral nerve (GFN) rises from the first and second lumbar nerves. The genital branch of the nerve passes under the inguinal ligament and over the symphysis pubis immediately lateral to 
the pubic tubercle. This sensory nerve then travels to the labia or scrotum. Vulnerable to trauma as it passes over the ramus of the pubis, the genitofemoral nerve can be injured as the result of blunt surgical trauma, and the pain tends to worsen with time. Pfannenstiel incisions for hysterectomy or cesarean section, and inguinal herniorrhaphy (especially with mesh because of the "bite" taken on Poupart's ligament) can result in chronic, intractable pain. A slowly developing cicatrix can entrap this nerve, and the pain generally develops months to years following the surgery. Less commonly, this nerve can be injured as the result of compression of the nerve during late pregnancy.

\section{Clinical Presentation}

The clinical presentation of genitofemoral, ilioinguinal, or iliohypogastric pathology consists of dull, aching pain in the lower lateral abdomen. This pain is worse with Valsalva's maneuver, cough, bowel movements and lifting. Patients will often experience increase in pain intensity and frequency with menstruation, salt intake, and sexual intercourse. Irritation of any of these nerves can result in referred pain to the testicle or vulva, interior thigh, or upper lumbar region. A localized tenderness and pain with digital pressure worsened during Valsalva's maneuver is observed. Occasionally the ilioinguinal nerve is trapped more laterally at the attachment of the external oblique onto the iliac crest. A "double crush" situation may result from pathology at both places, requiring the more proximal treatment for complete relief. The genitofemoral nerve entrapment is usually found at the pubic tubercle. Unfortunately, in the case of surgical scar entrapment, it may be difficult to address the pathology more proximally, since the nerve becomes intra-abdominal at that point.

A similar syndrome results from entrapment of the subgastric nerve, which arises from the T11 and T12 nerve roots and passes around anteriorly to the rectus sheath. This neuropathy results in an upper quadrant pain that may mimic cholecystitis or pancreatitis or may be caused by the surgical treatment of upper abdominal pathology.

\section{Technique}

After superficial infiltration with local anesthetic and deep infiltration with saline containing epinephrine 1:200,000, a 12-gauge intravenous catheter is used as the introducer for the $2.0 \mathrm{~mm}$ cryoprobe. After precise confirmation of probe placement employing the peripheral nerve stimulator, three-two minute cryo-cycles seem to be sufficient. Fluoroscopic localization may be useful for the identification of the nerves at the pubic tubercle or iliac crest in the obese patient.

Proximal treatment of the genitofemoral nerve is more problematic. The GFN runs most of its course along the surface of the psoas muscle. At laparotomy, the nerve can be easily visualized, and lesioned under direct vision. Saberski (47) has recently described and promoted the technique of pelvic pain mapping under sedation and minimal insufflation laparoscopy. His group has confirmed the GFN as a common cause of chronic pelvic pain, and they are developing techniques amenable to transabdominal lesioning under laparoscopic visualization.

\section{Sacral Neuralgia}

Perineal pain and coccydynia can be due to pathology of the sacral nerve roots. If the patient has failed NSAIDs and caudal epidurals, then coccygeal nerves blocks done bilaterally as the S5 nerve roots leave the sacral foramen may be an option. The diagnostic blocks assist in confirming the lack of rectal dysfunction, and predict the success.

\section{Technique}

The nerve is identified under fluoroscopy at the medial border of the sacral cornu, and sensory stimulation at 50 Hertz will aid in localization of the nerve. In the same way, cryoneuroablation of the dorsal S4 nerve roots can provide pain relief of the scrotum, vagina, perineum, and anus without affecting bowel or bladder function. The probe is either placed through the sacral hiatus up to the level of the fourth sacral foramen, or passed through the each foramen laterally to medially. Diagnostic transforaminal nerve blocks (I use a peripheral nerve stimulator and contrast to confirm location) will give a temporary block that allows the patient to "preview" the pain relief.

Occasionally, especially in the face of surgical scarring from multiple surgeries, the nerve must be addressed more proximally. Paravertebral nerve blocks under fluoroscopy, with a peripheral nerve stimulator at T12 or L1 (depending on the nerve target) will predict response to cryoneuroablation. If the diagnostic injections give temporary relief, cryoablation of the nerve root can give good relief distally into the groin of lower abdomen. The transverse process of the target nerve root is identified by fluoroscopy. After local anesthetic subcutaneous injection and saline with epinephrine infiltration, the 12-gauge catheter is advanced tangentially to the foramen, taking care not to advance into the foramen itself. The 2.0 $\mathrm{mm}$ probe is then advanced through the catheter, and, using the sensory stimulation mode, stimulation into the groin is obtained. Special care must be taken not to have motor stimulation down the leg, though motor stimulator into the groin is acceptable.

\section{Clinical Effectiveness}

Intraoperative lesioning of the ilioinguinal nerve during inguinal hernia repair adds only a minute to the procedure but can provide significant pain relief. After repair of the inguinal ring and the posterior wall, the ilioinguinal nerve is isolated and elevated onto a retractor. The cryoprobe is placed directly on the nerve and the freeze cycle initiated. A visible ice ball forms, and a one-minute freeze (with perhaps a second freeze cycle, taking care not to pull on the ice ball which can tear the nerve) should be adequate. Wood et a (48) first described cryoanalgesia after herniorrhaphy in 1979. Open cryoneurolysis of the ilioinguinal nerve was noted to decrease the analgesic requirements postoperatively. The follow up study in 1981 (49) looked at three groups of patients after hernia repair: those who received cryoneurolysis, paravertebral nerve blocks, or prn oral narcotics. Not only did the cryoneurolysis patients have less postoperative pain, but they also used fewer narcotics, ate a regular diet earlier, and returned to work faster. They were also able to use their abdominal muscles without pain. In contrast, Khiroya et al (50) found no significant difference in pain scores, pulmonary function, or analgesic use in a randomized, double-blinded study of 36 patients in 1986. Callesen et al (51) studied cryoneuroablation of the ilioinguinal and iliohypogastric nerves compared to sham cryoneuroablation, and found no statistical difference. The authors postulated that the post-herniorrhaphy pain might originate from deep muscle layers innervated by nerves other than the ilioinguinal and iliohypogastric nerves (such as the in- 
tercostal and the genitofemoral nerves). Abdominal wall pain relief, when diagnostic blocks have given excellent but only temporary relief, may be provided by cryoneuroablation. In one study, 15 patients with chronic abdominal pain underwent cryoneuroablation of the ilioinguinal and iliohypogastric nerves. Seven of the fifteen $(47 \%)$ noted good to excellent relief. Three of the seven had permanent relief, while the other four had relief lasting between 4 and 30 months (52). Raj (53) describes the use of cryoneuroablation of the ilioinguinal nerve to treat the abdominal pain of late pregnancy that results in severe traction on the ilioinguinal, especially if the nerve is tethered by scar tissue from prior surgery. Glynn (54) reported on the use of cryoanalgesia to treat pelvic pain at the symphysis pubis during pregnancy (most likely treating the genitofemoral nerve at that level).

Evans et al (55) performed cryoneurolysis of the lower three sacral nerve roots in 40 patients with intractable perineal pain; $78 \%$ of the patients received at least 30 days of relief. At the Hospital of the University of Pennsylvania, Love et al (56) described a novel cryolesion approach to the ganglion impar in a patient with rectal pain, noting more than six months of relief. Jain et al (57) described a case report of a 38 year old multiparous woman complaining of severe sacrococcygeal pain of 6 years' duration. The pain began after the birth of her second child, and was not relieved by oxycodone. Diagnostic blocks with $1 \%$ lidocaine on several occasions gave temporary relief, and a cryoprobe was inserted into the sacral extradural canal under fluoroscopy. Two sixty-second freeze cycles were performed, and the patient was noted to be pain free at follow up $11 / 2$ years later.

\section{Pudendal Neuralgia}

The pudendal nerve can be a cause of intractable perineal, vaginal, penile, scrotal, and rectal pain. Providing almost sole enervation of the perineum, the pudendal nerve arises from the $2^{\text {nd }}, 3^{\text {rd }}$, and $4^{\text {th }}$ sacral nerves in the pelvis, passes through the sciatic notch medial and inferior to the sciatic nerve and then crosses the ischial spine to enter the perineal region. Familiar to obstetricians, the pudendal nerve is often traumatized during vaginal deliveries. However, it can be a cause of pain in males and females, and may be triggered by trauma from bicycle seats, sur- gery, or perirectal infections. The pain is often hard for the patient to localize, and a meticulous physical exam, including rectal and pelvic exam, may be necessary to identify the nerve entrapment.

\section{Technique}

The nerve can be approached vaginally or percutaneously. The vaginal approach is a simple modification of the obstetrician's pudendal nerve block done during delivery to anesthetize the perineum. Using a modified Iowa trumpet with the patient in the lithotomy position, first the 12-gauge introducer and then the $2.0 \mathrm{~mm}$ probe are advanced through the trumpet to the ischial spine. Cryoneurolysis at this site will lead to profound hypoesthesia, including the possibility of loss of clitoral sensation. The percutaneous approach can be much more selective in the isolation of specific branches of the pudendal nerve. If the pain is primarily vaginal or penile, the patient is placed in a modified lithotomy position with the feet on the table instead of in stirrups. The 12gauge catheter is directed toward the sacrospinatus ligament instead of the ischial spine itself, and the $2.0 \mathrm{~mm}$ probe sensory stimulation is used to select the stimulation field needed. In the same way, if the pain is primarily rectal, the patient is positioned prone in a jackknife position, placing the 12-gauge catheter and then the 2.0 $\mathrm{mm}$ probe more inferiorly, using stimulation to direct the probe toward the rectal branches.

\section{Clinical Applications in Low Back ANd LoWer Extremity Pain}

\section{Facet Joint Pain Syndrome}

The most common use for cryoanalgesia for low back pain is the longterm treatment of lumbar facet pathology. When diagnostic lumbar facet blocks (either intraarticular or median branch blocks) have given good but only temporary relief, one option for further treatment is cryoneuroablation of the median dorsal rami.

\section{Clinical Presentation}

The clinical presentation, anatomy and innervation of the lumbar facet disease and pain syndrome have been described in many texts. Facet pain is often considered a "biomechanical "pain, typically made worse on movement, particularly with hyperextension. There may be significant myofascial spasms in the paravertebral region as the muscles try to "splint" the injured joint. Patients will often fail a physical therapy program because therapy will aggravate the pain. There are usually no neurologic signs despite the referred pain down the leg ("pseudosciatica"). X-rays may or may not show facet sclerosis, and there may be a history of trauma such as "whiplash" in the cervical region or twisting injuries in the lumbar region. Pain is transmitted to the spinal cord via the articular facet nerves, the nerves of Luschka, the dorsal median nerve, the meningeal nerves, the anterior communicating ramus, and other branches of the posterior ramus. Palpation reveals exquisite tenderness along the paravertebral muscles. Other biomechanical problems are also often seen, including leg discrepancy (functional vs anatomy), SI joint dysfunction, and scoliosis. Median branch blocks give a better predictive indication of potential success from cryoneuroablation than do intraarticular injections. Because the pain relief is expected to be temporary, it is critical to use the pain free period to facilitate a rehabilitation program. The success of the cryo lesion is a direct function of the patient selection, accurate probe placement and the rehabilitation.

\section{Technique}

The technique requires precise localization of the target nerve. The inferior border of the transverse process at the level of the inferior articular process is identified by fluoroscopy. When the introducer comes in contact with the target bone, the stylet is removed and the 2.0-millimeter probe is then advanced through the catheter and the tip of the probe exposed by withdrawing the catheter into the subcutaneous tissues.

Accurate and meticulous sensory stimulation is critical for success. As the probe moves across the periosteum in a medial to lateral direction, sensory stimulation $(100-\mathrm{Hz})$, first at 2 volts, and then as low as 0.5 volts is used to identify the median branch nerve. Particular care must be used in the movement of the probe, since the movement itself may cause a paresthesia that is not an actual sensory stimulation but rather a "piezoelectric" or traction effect. The procedure is repeated with progressively decreasing voltage, until stimulation can be reliably obtained at 0.5 volts. This position is usu- 
ally at the "neck of the Scottie dog", consistent with the position of a "collar". Another technique popularized by Sebastian Thomas (58), involves placing the probe at the junction of the transverse process and pedicle - the "Scottie dog's eye". At this time motor stimulation $(2-\mathrm{Hz})$ is used at its highest voltage to confirm that the probe is not too close to the spinal nerve root. Three 2 -minute freeze cycles are usually adequate.

\section{Clinical Effectiveness}

Brechner (59) studied the effects of percutaneous cryoneuroablation of the lumbar facet in patients with neck and low back pain. There was $70 \%$ pain relief after 1 hour and relief lasted 1 week. Pain relief decreased to $50 \%$ at 3 weeks, and by 3 months had returned to baseline. Schuster (60) studied 52 patients followed for a 13 month period. Forty-seven patients had significant relief of low back pain after cryoneuroablation, and only one patient had a repeat cryoneuroablation when the pain recurred after a 9-month pain free period. Ross (61) described 23 patients with complete but only short-term relief from lumbar facet blocks, who were treated with cryoneurolysis of the dorsal median nerve. Twentyone had complete relief for a follow up of six months to two years. Two patients had return of pain six to eight months later and underwent subsequent cryoneurolysis with complete relief. These studies are limited by a lack of certainty that the facet was the sole pain generator. Prognostic blocks, if performed, did not utilize currently recommended techniques.

Prognostic blocks should be performed one level at a time, one side at a time, and repeated to assure validity. All too often, pain generators are assumed based on a single trial of anesthetic (remember the placebo effect) with multiple levels injected and volumes of anesthetic far in excess of that needed to anesthetize the median dorsal ramus, a nerve a fraction of a millimeter in diameter. Small volumes, less than $0.2 \mathrm{~mL}$, are more than sufficient for adequate precision prognostic blocks. Volumes larger than that only serve to spread throughout the area and to confuse the issue.

As described above, it is well known that there is dual innervation of the facet joint. Median branch block diagnostic injections are commonly done both above and below the level of pathology.
However, complete denervation of the joint does not appear to be necessary for adequate pain relief. There are theoretic advantages to avoidance of a "Charcot" joint. In at least one case, an experienced pain physician treated another pain physician with a neurolytic facet block, resulting in a "Charcot joint" situation with resultant paraparesis when a listhesis developed at the treated segment (62). Fortunately, recovery ensued, but the concern about multiple neurolytic facet blocks is very real.

In addition, in "virgin backs" the goal is to provide a period of "analgesia" to allow appropriate rehabilitation; this does not necessarily require complete "anesthesia". My practice is usually to freeze only the most symptomatic level, with a goal of "good" rather than "complete" analgesia. Sensation to the joint is expected to return in two to six months as the nerve regenerates, but this time frame usually provides ample rehabilitation time, and most patients who have not undergone prior surgery will note long term relief. In patients with operated backs, however, the formation of post operative neuromas from the surgery itself, coupled with the surgical destabilizing of the posterior muscle and ligamentous structures, sets the stage for continued instability and pathology. Although these patients will also get relief with a cryoneuroablation, the effect is shorter lived due to the multiple pain generators. However, the procedure can be repeated, and it has not been uncommon in my practice to have post laminectomy patients returning every six to eight months to have the facet nerves refrozen but noting significant relief in the interim.

\section{Pseudosciatica}

Since Mixter and Barr (63) described herniations of the nucleus pulposus as a cause of pain going down the leg, the term "sciatica" has become synonymous with herniated discs. The definition of sciatica from Taber's Cyclopedic Medical Dictionary is "compression or trauma of the sciatic nerve or its roots, especially that resulting from ruptured intervertebral disc". However, both physicians and patients use the term to describe pain going down the leg, despite the fact that there are several clinical entities that will cause similar or identical pain going down the leg which are not related to disc disease. These are termed "pseudosciaticas", and several are quite amenable to treatment with cryoneuroablation. While facet pathology could also be considered a "pseudosciatica", this section will discuss interspinous ligament pathology, superior gluteal neuralgia, and cluneal neuralgia.

\section{Intraspinous Ligament}

The intraspinous segment of the dorsal ramus (ISDR) is the termination of the medial branch of the dorsal ramus of the spinal nerve. Injury to the soft tissues of the axial skeleton occur as the result of hyperextension or hyperflexion of the spine with injury to the ligamentous structures between the spinous processes, segmental muscle spasm and bursitis. The ISDR is responsible, in large part, for sensory innervation of these structures. Irritation of this nerve will refer pain down the leg (one or both sides) in a dermatomal pattern consistent with the level involved (64, $65)$. This pathology is seen commonly after spinal surgery, and patients will present with well-localized midline tenderness with localized swelling over the intervertebral space and may benefit from injection of small volumes of local anesthetic and steroid solutions. When this provides only temporary relief, cryoneuroablation may be indicated.

\section{Technique}

With the patient in the prone position, a large pillow is placed under the abdomen, and the patient is thereby flexed forward. Local anesthetic is infiltrated 2 $\mathrm{cm}$ lateral to the targeted interspace. Infiltration with local anesthetic containing epinephrine 1:200,000 is performed deeply until contact is made with the lamina. The $2.0 \mathrm{~mm}$ probe is passed via a $12-$ gauge introducer aimed at the junction of the lamina and the spinous process. A nerve stimulator is used to ensure that the probe is away from the spinal nerve itself. This procedure is performed bilaterally at each desired level, and can be performed with fluoroscopic guidance, or can be done using bony landmarks.

\section{Clinical effectiveness}

Klein and Trescot (66) reported in a poster presentation in 1994 on the clinical effectiveness of the cryoneurolysis technique.

\section{Superior Gluteal Nerve}

Superior gluteal nerve (SGN) entrapment may also be a source of pseudosciat- 
ica. The superior gluteal nerve, formed from the posterior branches of L4, L5, and $\mathrm{S} 1$, passes from the pelvis above the piriformis muscle. Deep to the gluteus maximus and medius muscles, the nerve accompanies the superior gluteal artery and vein over the surface of the gluteus minimus muscle. It supplies the gluteus medius and gluteus minimus muscles and innervates the tensor fascia lata muscle by a branch, which accompanies the lower branch of the deep division of the superior gluteal artery.

\section{Clinical Presentation}

Neuralgia due to irritation of the superior gluteal branch (SGN) of the sciatic nerve is commonly seen after a lifting injury involving the lower back and hip. After exiting the sciatic notch, the SGN passes caudal to the inferior border of the gluteus minimus, and penetrates the gluteus medius. Vulnerable as it passes in the fascial plane between the gluteus medius and gluteus minimus musculature, the SGN is injured as a result of shearing between the gluteal musculature with forced external rotation of the leg, and with extension of the hip under mechanical load. Rarely, this nerve is injured with forced extension of the hip, as might occur in a head-on automobile collision where the foot is pressed against the automobile floorboards with the knee in extension, as the patient anticipates impact. The clinical presentation consists of sharp pain in the lower back, dull pain in the buttock, and vague pain to the popliteal fossa and occasionally down to the foot. Patients generally experience pain with prolonged sitting, leaning forward, or twisting to the contralateral side. Often, patients will describe a "giving away" of the leg. Patients will sit with the weight on the contralateral buttock, or cross legs in such a manner as to minimize pressure on the involved side. Patients will sit with the weight on the contralateral buttock, or cross legs in such a manner as to minimize pressure on the involved side (67). Clinically the presentation can be similar to SI pathology, but examination will show the SI tenderness medial to the posterior iliac crest while the SGN is more lateral. Diagnostic blocks under fluoroscopy, with nerve stimulation, are critical for accurate diagnosis, since it is easy to confuse this nerve with a piriformis entrapment syndrome or the myofascial pain of the gluteus medius muscle itself.

\section{Technique}

With the patient in the prone position, the medial border of the ilium is palpated. The nerve is located $5 \mathrm{~cm}$ lateral and inferior to the attachment of the gluteus medius. Infiltration with local anesthetic is followed by a saline solution with epinephrine 1:200,000. A 12-gauge intravenous catheter is again used as the introducer for the $2.0 \mathrm{~mm}$ cryoprobe. The nerve is approached from superior-medial and the probe is directed inferior-laterally. The peripheral nerve stimulator is employed to ensure the avoidance of motor nerves (e.g., sciatic nerve).

Prospective data regarding clinical and/or cost effectiveness have not yet been reported.

\section{Sacroiliac Joint Pain}

Prior to 1934, the sacroiliac joint was considered the most common cause of idiopathic low back pain (59). However, that was the year Mixter and Barr described the herniated nucleus pulposus. The sacroiliac joint then was ignored for many years. The difficult of imagining this joint also contributed to its obscurity. New appreciation of the SI joint as a cause of lumbosacral and leg pain has been triggered by new diagnostic physical exam techniques, injection approaches, and treatment options. It is estimated that $22 \%$ of low back pain (and 33\% of low back pain in elementary and high school students) is from SI pathology (68).

\section{Clinical Presentation}

The SI joint is not fused as often taught but rather is a joint with a fibrous lateral surface and a cartilaginous medial surface. The joint is designed to lock while in stance position and unlock as part of the stride. It is therefore vulnerable to "dislocation" and "jamming". Slamming on brakes during motor vehicle collisions or falling on the buttocks, or a sudden twisting injury can cause pain in the buttocks radiating down the leg. Physical exam shows tenderness at the medial aspect of the posterior iliac crest -the "Fortin Finger Test" (69) - and diagnosis is confirmed by fluoroscopic injection of local anesthetic and contrast into the joint with subsequent resolution of pain.

The innervation of the sacroiliac joint is primarily by way of the dorsal rami of S1 through S3 (70). Because these nerves enter the spinal column at the level of the leg nerves, pathology of the sacro- iliac joint will refer pain down the leg in a radicular pattern. The most common innervation in my experience is usually S2. The exiting dorsal ramus leaves the foramen usually at the 4 o'clock position on the right and the 8 o'clock position on the left. A diagnostic block using a peripheral nerve stimulator can aid in the determination of the most significant level of nerve innervation, and a small dose of contrast will outline the nerve root, giving a good "road map" for the subsequent cryoneuroablation procedure. The subcutaneous structures overlying the joint are innervated by branches of the L5-S1 facet nerves (discussed above) and medial cluneal (below).

\section{Technique}

For the cryoneuroablation procedure, the patient is positioned prone and the target sacral foramina identified by fluoroscopy. After a prep, a small dose of local anesthetic is infiltrated subcutaneously, and deeper infiltration is performed with the saline/ epinephrine solution, again about $1 \mathrm{~mL}$. After a small skin nick is made, the 12gauge introducer is advanced to the inferior border of the foramen laterally (as described above, at 4 o'clock on the right and 8 o'clock on the left). The stylus is then removed and the $2.0 \mathrm{~mm}$ probe advanced through the catheter. Using the stimulation pattern described for facets, the area of maximal stimulation is identified. Care must be taken to avoid actually cannulating the foramen since this could potentially affect the nerves to the bowel and bladder.

Lloyd et al (10) and Evans et al (12) used cryoanalgesia to treat the sacral nerve roots in patients with intractable "sciatica' and perineal pain. Prospective data regarding clinical and/or cost effectiveness have not yet been reported.

\section{Cluneal Neuralgia}

The superior cluneal nerves are an underrecognized source of hip, back, and leg pain. These nerves are the lateral cutaneus branches of the dorsal rami of the upper three lumbar nerves (71). They pierce the quadratus lumborum fascia at the lateral border of the erector spinae muscle, cross the iliac crest a short distance in advance of the posterior iliac spine, and distribute to the skin of the gluteal region as far as the greater trochanter. 


\section{Clinical Presentation}

Two recognized nerve pathologies will cause pain in this region. The pathology is of the cluneal nerve itself, either after surgical iliac crest graft harvesting, or, much more commonly, secondary to entrapment of the nerve as it pierces the quadratus lumborum fascia. Thus the muscle spasm of a "pulled muscle" would entrap the cluneal nerve, causing a referred pain down the leg, potentially all the way to the foot. This "pseudosciatica" would clinically mimic a radiculopathy. Diagnosis is made by physical exam, since palpation of the iliac crest will be markedly tender and will usually replicate the leg pain. At fluoroscopy, the maximal tenderness is usually seen at the medial iliac crest, and a traction spur of the attachment of the quadratus lumborum is often seen just medial to the area of maximal tenderness. Injection of $1 \mathrm{~mL}$ of local anesthetic utilizing a peripheral nerve stimulator is diagnostic and deposteroids at this spot are often very effective in completely relieving the pain. If the relief is complete but only temporary, placement of the cryo probe at that same spot (confirmed by maximal sensory stimulation and devoid of motor stimulation) utilizing the technique previously discussed, can give dramatic and long-term relief.

Maigne's syndrome is a T12/L1 facet pathology referring pain to the iliac crest via the cluneal nerves. There is tenderness of the skin over the iliac crest, and the diagnosis is made by the use of a thoracolumbar (T12-L1) facet block. Treatment would then include cryoneuroablation of the median branch at that level, identical to that described above for lumbar facets.

\section{Technique}

The initial steps are as described above, and as noted, accurate and meticulous sensory stimulation is critical for success. As the probe moves across the periosteum, sensory stimulation at first at 2 volts, 1 volt, and then 0.5 volts is used to identify the cluneal nerve. Small movements of the probe are used as described above. The position is where the quadratus lumborum attaches to the periosteum. At this time motor stimulation is used at its highest voltage to confirm that the probe is not too close to the L5 nerve root. Gas flows are then turned up to ten to 12 liters per minute and a series of three two minute freezes with thirty seconds de- frosting between each cycle is performed as for the facet cryoneuroablation. There is usually a burning pain on initiation of the first freeze cycle which often replicates the pain and should resolved within approximately 30 seconds.

\section{Clinical Effectiveness}

Saberski et al (62) in 2000 described a syndrome of "painful iliac crest donor site" in a patient who had undergone iliac crest bone harvesting for a lumbar fusion. This patient experienced one year of complete relief after cryoneuroablation of the region of the iliac crest. Although this was not identified as the cluneal nerve, the clinical description appears to be consistent with a cluneal nerve pathology.

Long-term (in excess of 5 years) relief has been obtained with open cryoneurolysis of cluneal nerves injures during bone graft harvesting. Noback (73) in 1999 presented a technique of exposure of the graft site by re-opening the surgical incision with dissection to the iliac crest. Cluneal neuromata are often found where the chiseled nerve has retracted to the upper anterior (abdominal) portion of the graft site. After exposure and stimulation during the procedure performed with local anesthetic, the severed nerve is cryoablated just proximal to its severed end with the $2 \mathrm{~mm}$ probe according to previously described techniques.

\section{Lower Extremity Pain}

Neuralgia due to irritation of the infrapatellar branch of the saphenous nerve is seen weeks to years after blunt injury to the tibial plateau, or following knee replacement. The nerve is vulnerable as it passes superficially to tibial collateral ligament, piercing the sartorius tendon and fascia lata, inferior to the medial tibial condyle. The clinical presentation consists of dull pain in the knee joint, and achiness below the knee. Patients have trouble localizing the pain and tend to ambulate in such a manner as to minimize flexion of the knee joint. Physical exam shows tenderness to palpation just inferior to the medical tibial plateau. Pain with digital pressure is diagnostic, and most patients respond extremely well to a small volume local anesthetic and deposteroid injection. Cryoneuroablation can be very useful for those patients in whom the injection gives only temporary relief.

\section{Technique}

A 12-gauge intravenous catheter is used as the introducer for the $2.0 \mathrm{~mm}$ cryoprobe, employing three-two minute cryo-cycles. Special care must be taken to prevent frostbite injury to the skin. Approaching the nerve from a caudad to cephalad direction and keeping the probe positioned at an acute angle will help keep the ice ball below skin level and thereby decrease the frostbite risk.

Neuralgia due to irritation of the superficial peroneal and saphenous nerves can be seen weeks to years after injury to the foot and ankle. These superficial sensory nerves pass through strong ligamentous structures, and are vulnerable to stretch injury with inversion of the ankle, compression injury due to edema, and sharp trauma due to bone fragmentation.

The superficial peroneal nerve runs superficial and medial to the lateral malleolus, and continues superficial to the inferior extensor retinaculum, terminating in the 4th and 5th toes. Particularly vulnerable to injury following sprains of the lateral ankle, the clinical presentation consists of dull ankle pain, worse with passive inversion of the ankle. Signs and symptoms consistent with reflex sympathetic dystrophy or CRPS (a disproportionate swelling, vasomotor instability and allodynia) are remarkably common. Patients tend to ambulate in such a manner as to minimize weight bearing on the lateral aspect of the foot. Pain with digital pressure in the area between the lateral malleolus and extensor retinaculum is diagnostic. Sometimes the patients are so diffusely tender that it is hard to determine where the worst tenderness is. The history can be very helpful here, because the mechanism of injury is consistent enough that almost all of these injuries result in superficial peroneal neuralgia. Small volume diagnostic injections with local anesthetic and deposteroid can give rapid and dramatic relief, sometimes decreasing the swelling "right before your eyes". The saphenous nerve at the ankle passes anterior to the medial malleolus, and is injured by evertion ankle trauma. The pain, swelling, and hyperesthesia from this entrapment can also result in an "RSD" syndrome. Pain will radiate up the medial shin and down to the great toe, but the patient may have difficult identifying the exact location, it is important, therefore to explore the mechanism of injury to predict the likely pathology. 


\section{Technique}

A 12-gauge intravenous catheter is used as the introducer for the $2.0 \mathrm{~mm}$ cryoprobe, employing three-two minute cryo-cycles. Special care must be taken to prevent frostbite injury to the skin. Approaching the nerve from a caudad to cephalad direction and keeping the probe positioned at an acute angle will help keep the ice ball below skin level and thereby decrease the frostbite risk.

\section{Obturator Nerve}

The obturator nerve is rarely a pain problem except in cases of spasticity. It has, however, also been observed after surgical manipulation and in association with retroperitoneal hemorrhage. The obturator nerve has both sensory and motor components, and provides sensation to the medial distal thigh and knee. Diagnostic blocks may be useful in the evaluation of hip pain, since the articular branch of the obturator nerve is involved with sensation to the hip. The obturator is formed from branches of the $2^{\text {nd }}$ and $3^{\text {rd }}$ sacral nerve roots, and passes anteriorly into the pelvis and then out onto the thigh via the obturator canal.

\section{Technique}

The patient is placed supine, with the affected limb abducted slightly. Fluoroscopy may be useful in the obese or severely spastic patient. The pubic tubercle is the palpated, and local anesthetic is infiltrated subcutaneously approximately one fingerbreadth laterally and inferiorly to the tubercle. After saline with epinephrine infiltration, the 12-gauge catheter is carefully and gently advanced to the inferior border of the ramus. If done blindly, hitting the edge of the ramus will confirm depth. If done under fluoroscopy, the catheter can be directed to just below the inferior border of the ramus. To treat spasticity, this is one of the few times that motor stimulation for localization is appropriate. Adduction of the thigh at low voltages $(0.5$ to $1 \mathrm{mV})$ will confirm position. Spastic muscles should relax quickly, usually during the first freeze cycle. For pain, on the other hand, localization with the sensory mode is more effective, and an effort is made to avoid strong motor simulation if repositioning is possible.

\section{Clinical Effectiveness}

Kim and Ferrante (74) reported cryoneuroablation of the obturator nerve for the treatment of adductor spasticity and obturator neuropathy. However, with the increased use of botulism toxin, this technique may be less useful.

\section{Deep Peroneal Nerve}

The deep peroneal nerve runs beneath the tendon of the extensor hallucis brevis, superficial to the dorsal interosseous muscle, between the first and second metatarsal heads, terminating in the 1 st and 2 nd toes. Diabetics and woman seem to be most vulnerable to this compression injury that results from tightly fitting shoes. Seen less commonly following blunt injury to the dorsum of the foot, the clinical presentation consists of dull pain in the great toe, often worse after prolonged standing. There may also be pain at ball of the foot, poorly localized and occasionally burning in nature. Patients tend to ambulate in such a manner as to minimize weight bearing on the anterior foot. Pain with digital pressure in the area between first and second metatarsal heads (especially with concomitant pressure on the metatarsal heads) is diagnostic. Morton's neuromas (digital neuromas, intermetatarsal space neuromas) will present similarly but are located between the second and third metatarsal space or between the third and fourth. Neuromas that have not been surgically treated are easier to treat because there is room for the large $(2.0 \mathrm{~mm})$ probe, which increases the success rate. Unfortunately, many patients are only sent for evaluation after the surgical treatment has failed. The cryo probe must then be placed proximal to the surgical trauma to be effective, and there is not much room in the proximal portion of the metatarsal triangle apex, necessitating the use of the smaller $(1.4 \mathrm{~mm})$ probe.

\section{Technique}

The appropriate introducer (12gauge for "virgin" nerves and the 1.4gauge for postoperative neuromas) is introduced through the skin perpendicular to the nerve and directed toward the apex of the metatarsal bones. Care must be used with the saline and epinephrine, because of the risk of digital ischemia. Placing the non-introducing hand at the plantar surface will detect if the probe is too close to the skin of the sole of the foot. Stimulation should replicate the patient's usual pattern of pain.

\section{Clinical Effectiveness}

Cryoneurolysis of an intermetatarsal space neuroma has been reported to provide at least six months of relief (75). Wang (76) performed percutaneous cryoneurolysis on various peripheral nerves (ulnar, median, sural, occipital, palmar branch of the median, and digital) in 12 patients with six patients reporting relief of one to twelve months' duration.

\section{Medial and Lateral Calcaneal Nerves}

Heel pain, especially on the plantar surface, is often diagnosed as plantar fasciitis. However, occasionally the heel pain is caused instead by entrapment of the medial and less commonly the lateral calcaneal nerves. The medial calcaneal nerve is a terminal branch of the posterior tibial nerve, and passes under the flexor retinaculum at the bony attachment of the abductor hallucis. The small overhang of bone is the site of entrapment and the target for the cryo lesion. A similar anatomy exists laterally, though the bony outcropping is less distinct and therefore a harder landmark to find.

\section{Technique}

A 14-gauge intravenous catheter is used as the introducer for the $1.4 \mathrm{~mm}$ cryoprobe, employing three-two minute cryo-cycles. Care must be used to avoid frostbite, and the technique seems to work best when the probe is directed cephalad to caudad along the groove in the bone.

\section{Peripheral Neuropathy}

Patients who have been diagnosed as having peripheral neuropathies may actually have distal nerve entrapments. Dellon (77) stated that it was "possible to restore sensation and relieve pain in $80 \%$ of patients with symptoms of diabetic neuropathy by decompressing multiple peripheral nerves." He described surgical decompression techniques, but similar results should be available through the use of cryoneuroablation. The digital, superficial peroneal, and saphenous nerves described above have been implicated in all or a vast majority of the foot pain attributed to peripheral neuropathy.

\section{Clinical Effectiveness}

Milleret (78) described the use of cryoanalgesia in elderly patients with distal arteritis. 
Clinical Applications in Upper Extremity Pain

\section{suprascapular nerve}

The suprascapular nerve arises from the upper trunk of the brachial plexus and travels downward and laterally to pass through the suprascapular notch to provide innervation to the supraspinatus, in fraspinatus and the shoulder joint. Clinically the patient complains of a poorly localized upper shoulder pain, usually triggered by a lifting injury with the arm internally rotated. Tenderness is elicited by palpation of the suprascapular notch (the "Vulcan death grip"). Diagnostic blocks should be performed utilizing a peripheral nerve stimulator.

\section{Technique}

The patient is positioned prone with the chest supported on pillows, letting the arm hang anteriorly. Alternatively, the patient can be positioned seated with the affected arm hanging by the patient's side. The 12-gauge intravenous catheter is advanced into the supraspinatus notch parallel to the direction of the nerve, perpendicular to the scapula. Consider using fluoroscopic guidance to locate the superior border of the scapula if the scapula is not easily palpated. The $2.0 \mathrm{~mm}$ probe is then advanced through the catheter and the nerve is identified using sensory or motor stimulation, this being one of the few mostly motor nerve amenable to cryoneuroablation.

\section{Superficial Radial Nerve}

The superficial radial nerve runs under cover of the brachioradialis into the forearm and onto the posterior surface of the wrist to supply the skin along the radial portion of the wrist and fingers including portions of the dorsum of the hand. This is the nerve injured when the hand is bumped on a table, the classic "trivial injury" resulting in sympathetic stimulation. This nerve is also injured after chronic wrist movements and Colles' fractures.

\section{Technique}

The area of maximal tenderness is identified, usually between the brachioradialis and extensor carpi radialis muscles. If possible, the 12-gauge intravenous catheter is used, advanced proximally parallel to the nerve. The $2.0 \mathrm{~mm}$ probe is then placed through the cathe- ter. Sometimes the tissues in this area are too tight to accept the larger probe, and the 14-gauge catheter and $1.4 \mathrm{~mm}$ probe must be used.

\section{Clinical Effectiveness}

Wang (66) performed percutaneous cryoneurolysis on various peripheral nerves (ulnar, median, sural, occipital, palmar branch of the median, and digital) in 12 patients with six patients reporting relief of one to twelve months' duration.

\section{Clinical Applications in Special Cases}

Cryoneuroablation is a technique uniquely suited for sensory nerves. There are, however, a few situations where cryoneuroablation of a motor or mixed motor nerve is appropriate. A case is presented as illustration.

An 89-year old man presented with intractable right leg pain, preventing ambulation. MRI revealed a synovial cyst in the foramen of the right L4 nerve root. Transforaminal epidural at that level with one $\mathrm{mL}$ of local anesthetic gave excellent but only temporary relief. While the local anesthetic was in effect, the patient was able to ambulate with a walker without pain, but he returned to bedbound status when the local anesthetic wore off. The patient was not a surgical candidate because of severe coronary artery disease, poorly controlled diabetes, and $\mathrm{O} 2$ dependent COPD. The patient and family elected to proceed with cryoneuroablation of the nerve root in an effort to provide pain relief. Although there was significant leg weakness post procedure, the improvement in function was dramatic, and he continued to be able to ambulate with a walker until his death several months later.

In a similar situation, the $2 \mathrm{~mm}$ cryoprobe has been used to extract a synovial cyst at a L4-5 facet after it was demonstrated that the cyst evaginated and impinged on the exiting nerve root. The probe was placed on the medial cyst after its distension with contrast in a translaminar fashion. After a brief period of freezing, 20 seconds, the probe was removed without defrosting. The resulting tear in the facet capsule decompressed the nerve with long-term improvement (79).

\section{ConcLusion}

In conclusion, cryoneuroablation is an effective interventional pain management technique, providing significant analgesia in an outpatient or office setting.
The effect is routinely reversible, relatively painless, and is not associated with neuroma formation. An accurate diagnosis with specific diagnostic injections of small volumes of local anesthetic and meticulous localization of the nerve is critical for successful outcome. Remember, "You can not treat what you can not diagnose."

\section{Author Affiliation: \\ Andrea M. Trescot, MD \\ Medical Director \\ The Pain Center \\ 1564 Kingsley Ave \\ Orange Park, FL 32073 \\ E-mail: amt57@aol.com}

\section{REFERENCES}

1. Frost R. Fire and Ice, 1923.

2. Hippocrates. Heracleitus on the Universe. , Aphorisms, Vol. 4. Heinemann, London, 1931; 5:165, 7:201.

3. Breasted JG. University of Chicago Oriental Institute Publications, Vol III, University of Chicago Press, Chicago, 1930, p 217.

4. Gruner OC. A Treatise on the Canon of Med icine of Avicenna. Luzac, London, 1930.

5. Larre' D. Surgical Memoirs of the campaigns of Russia, Germany and France. Carey \& Lea, Philadelphia, 1832.

6. Evans P. Cryoanalgesia. The application of low temperatures to nerves to produce anesthesia or analgesia. Anaesthesia 1981; 36:1003-1013.

7. Arnott J. On severe cold or congelation as a remedy. London Medical Gazette, 1848.

8. Arnott J. On the treatment of cancer by the regulated application of an anesthetic temperature. J Churchill, London, 1851:32-54.

9. Richardson BW. Med Times and Gazette, 1866; 1:115.

10. Trendelenberg W. Uber Landauende Nerveausschaltung mit siche Regenerationsfahigkeit. Zeitschrift fur die gesamte experimentelle Medizin 1917; 5:371-374.

11. Cooper IS, Grissman F, Johnson R. St Barnab Hosp Med Bull 1962:11-16.

12. Amoils SP. The Joules Thompson cryoprobe. Arch Ophthalmol 1967; 78:201-207.

13. Lloyd JW, Barnard JDW, Glynn CJ. Cryoanalgesia, a new approach to pain relief. Lancet 1976; 2:932-934.

14. Warfield CA. Cryoanalgesia: Freezing of peripheral nerves. Hospital Practice 1987:71-77.

15. Barnard JD, Lloyd JW. Cryoanalgesia. Nurs Times 1977; 73:897-899.

16. Barnard $D$. The effects of extreme cold on sensory nerves. Ann R Coll Surg Engl 1980; 62:180-187.

17. Evans PJ, Lloyd JW, Green CJ. Cryoanalgesia: The response to alterations in freeze cycle and temperature. Br J Anaesth 1981; 53:1121-1126. 
18. Garamy G. Engineering aspects of cryosurgery. In Rand RW, Rinfret A, von Leden H (eds). Cryosurgery, Charles C. Thomas, Springfield, 1968.

19. Evans PJ, Lloyd JW, Jack TM. Cryoanalgesia for intractable perineal pain. J $R$ Soc Med 1981; 74:804-809.

20. Myers RR, Powell HC, Heckman HM et al. Biophysical and pathological effects of cryogenic nerve lesion. Ann Neurol 1981; 10:478-485.

21. Sunderland S. Nerves and Nerve Injuries. Edinburgh \& London: Livingstone, 1968:180.

22. Holden H. Practical Cryosurgery, 2-3. Pitman, London, 1975, p 9.

23. Gander M, Soanes WA, Smith V. Experimental prostate surgery. Investig Urol 1967; 1:610.

24. Soanes WA, Ablin RJ, Gander MJ. Remission of metastatic lesions following cryosurgery in prostate cancer: Immunologic considerations. J Urol 1970; 104:154.

25. Myers RR, Heckman HM, Powell HC. Axonal viability and the persistence of thermal hyperalgesia after partial freeze lesions of nerve. J Neurol Sci 1996; 139:28-38.

26. Raj P. Practical Management of Pain. Cryoananalgesia. Year Book Medical Publishers, Chicago, 1986, p 779.

27. Johannesen N, Madsen G, Ahlburg P. Neurological sequelae after cryoanalgesia for thoracotomy pain relief. Ann Chir Gynaecol 1990; 79:108-109.

28. Klein IDS, Edwards LW, Klein PW. Treatment of cryptogenic earache with posterior auricular nerve block. Am Acad Pain Manag, 1992.

29. Wallace MS, Leung AY, McBeth MD. "Malignant Pain.” In Raj PP (ed). Textbook of Regional Anesthesia. Churchill Livingstone, New York, 2002, p 572.

30. Bernard J, Lloyd J, Glynn C. Cryosurgery in the management of intractable facial pain. BrJ Oral Surgery 1998-1999; 16:135.

31. Barnard D, Lloyd J, Evans J. Cryoanalgesia in the management of chronic facial pain. J Maxillofac Surg 1981; 9:101-102.

32. Nally FF, Flint SR, Bennett SD et al. The role of cryotherapy in the management of paroxysmal trigeminal neuralgia - an analysis of 112 patients. J Irish College Phys \& Surg, 1984 .

33. Nally FF. A 22-year study of paroxysmal trigeminal neuralgia in 211 patients with a 3year appraisal of the role of cryotherapy. Oral Surg Oral Med Oral Path 1984; 58:17-23.

34. Zakrzewska JM, Nally FF. The role of cryotherapy (cryoanalgesia) in the management of paroxysmal trigeminal neuralgia: A six-year experience. Br J Oral Maxillofac Surg 1988; 26:18-25.

35. Zakrzewska JM. Cryotherapy for trigeminal neuralgia: A 10-year audit. Br J Oral Maxillofac Surg 1991; 29:1-4.

36. Robinson SR, Purdie GL. Reducing posttonsillectomy pain with cryoanalgesia: A randomized controlled trial. Laryngoscope 2000; 110:1128-1131.
37. Nelson KM, Vincent RG, Bourke RS et al. Intraoperative intercostal nerve freezing to prevent post-thoracotomy pain. Ann Thorac Surg 1974; 18:280-285.

38. Glynn CJ, Lloyd JW, Barnard JD. Cryoanalgesia in the management of pain after thoracotomy. Thorax 1980; 35:325-327.

39. Orr IA, Keenan DJM, Dundee JW. Improved pain relief after thoracotomy: Use of cryoprobe and morphine infusion. $\mathrm{Br}$ Med J 1981; 283:945-948.

40. Orr IA, Keenan DJK, Dundee JW et al. Postthoracotomy pain relief: Combined use of cryoprobe and morphine infusion. Ann $R$ Coll Surg Engl 1983; 65:366-369.

41. Riopelle JM, Everson C, Moustoukos N et al. Cryoanalgesia: Present day status. Seminars in Anesthesia, 1985; 4:305-312.

42. Maiwand O, Makey A. Cryoanalgesia for the relief of pain after thoracotomy. Brit Med J 1981; 282:1749-1750.

43. Johannesen N, Madsen G, Ahlburg P. Neurological sequelae after cryoanalgesia for thoracotomy pain relief. Ann Chir Gynaecol 1990; 79:108-109.

44. Brichon PY, Pison C, Chaffanjon PH et al. Comparison of epidural analgesia and cryoanalgesia in thoracic surgery. Eur Cardiothorac Surg 1994; 8:482-486.

45. Green CR, DeRosayro AM, Tait AP et al. Longterm follow-up of cryoanalgesia for chronic thoracic pain. Reg Anesth 1993; 18:46.

46. Jones M, Muffin KR. Intercostal block with cryotherapy. Ann R Coll Sug Engl 1987; 69:261-262.

47. Rosser JC, Goodwin M, Gabriel NH et al. The use of mini-laparoscopy for conscious pain mapping. Tech Reg Anesth Pain Manage 2001; 5:152-156.

48. Wood G, Lloyd J, Evans P et al. Cryoanalgesia and day case herniorrhaphy. (Letter) Lancet 1979; 2:479.

49. Wood G, Lloyd J, Bullingham R et al. Post operative analgesia for day case herniorrhaphy patients. A comparison of cryoan algesia, paravertebral blockade and ora analgesia. Anaesthesia 1981; 36: 603-610.

50. Khiroya RC, Davenport HT, Jones JG. Cryoanalgesia for pain after herniorrhaphy. Anaesthesia 1986; 41:73-76.

51. Callesen T, Karsten B, Thorup J et al. Cryoanalgesia: effect on postherniorrhaphy pain. Anesth Analg 1998; 87:896-899.

52. Racz G, Hagstrom D. Iliohypogastric and ilioinguinal nerve entrapment: Diagnosis and treatment. Pain Digest 1992; 2:43-48.

53. Raj P. Practical Management of Pain. In Cryoananalgesia. Year Book Medical Publishers. Chicago 1986, p 779.

54. Glynn C), Carrie LE. Cryoanalgesia to relieve pain in diastasis of the symphysis pubis during pregnancy. $\mathrm{Br} \mathrm{Med} \mathrm{J} \mathrm{1985;} \mathrm{290:}$ 1946-1947.

55. Evans PJ, Lloyd JW, Jack TM. Cryoanalgesia for intractable perineal pain. J $R$ Soc Med 1981; 74:804-809.
56. Loev MA, Varklet VL, Wilsey BL et al. Cryoablation: A novel approach to neurolysis of the ganglion impar. Anesthesiology 1998; 88:1391-1393.

57. Jain S, Rooney SM, Goldiner PL. Managing the cancer patient's pain. Female Patient 1983; 8:1-11.

58. Saberski LR, Trescot AM, Klein DS. Cryoneurolysis in clinical practice. In Waldman SD, Winnie AP (eds). Interventional Pain Management, WB Saunders Co., Philadelphia, 1994, chapter 16.

59. Brechner T. Percutaneous cryogenic neurolysis of the articular nerve of Luschka. Regional Anesth 1981; 6:18-22.

6o. Schuster GD. The use of cryoanalgesia in the painful facet syndrome. J Neurol Orthopaed Surg 1982; 4:271-274.

61. Ross EL. Cryoneurolysis of lumbar facet joints for the treatment of chronic lower back pain. Presented at the American Society of Regional Anesthesia, April 6, 1991.

62. Trescot AM, Noback CR. Cryoanalgesia in low back pain. In: Manchikanti L, Slipman C, Fellows B (eds). Low Back Pain, Diagnosis and Treatment. ASIPP Press, Paducah, KY; 2002, pp 473-482.

63. Mixter WJ, Barr JS. Rupture of the intervertebral disc with involvement of the spinal canal. N Engl J Med 1934; 211:210-215.

64. Feinstein $\mathrm{R}$ et al. Experiments on pain referred from deep somatic tissues. J Bone Joint Surg 1954; 36A:981-997.

65. Kellgren $\mathrm{JH}$. On the distribution of pain arising from deep somatic structures with charts of segmental pain areas. Clin Science 1939; 4:35-46.

66. Klein DS, Trescot AM. Dorsal median nerve cryoanalgesia. American Pain Society 1994 poster.

67. Trescot AM, Klein DS, Edwards LW. Superior gluteal nerve pathology as a cause of sciatica. AAPM abstracts, Sept 1995.

68. Bernard PN, Cassidy JD. Sacroiliac joint syndrome: Pathophysiology, diagnosis and management. In Frymoyer J (ed). The Adult Spine: Principles and Practice. Raven Press, New York, 1991 pp 2107-2131.

69. Fortin JD, Falco FJE. The Fortin finger test: An indicator of sacroiliac pain. Am J Orthop 1997 26:477-480.

70. Fortin JD, Kissling RO, O'Connor BL et al. Sacroiliac joint innervation and pain. Amer J Ortho 1999; 28: 687-690.

71. Woodburne RT. Essentials of Human Anatomy. Oxford University Press, 1957, pp 501-521.

72. Saberski LR, Ahmad M, Munir M et al. Identification of a new therapeutic approach for prolonged pain relief in chronic iliac crest donor site pain: A case report. Pain Clinic 2000 2:37-40.

73. Noback CR. Interventional Pain Management Techniques and Technologies, Bethesda, MD, June 1999.

74. Kim PS, Ferrante FM. Cryoanalgesia: A novel treatment for hip adductor spasticity and obturator neuralgia. Anesthesiology 1998; 89:534-536. 
75. Hodor L, Barkal K, Hatch-Fox LD. Cryogenic de nervation of the intermetatarsal space neuroma. J Foot Ankle Surg 1997; 36:311-314.

76. Wang JK. Cryoanalgesia for painful peripheral nerve lesions. Pain 1985; 22:191-194.
77. Dellon AL. Decompression of peripheral nerves for symptoms of diabetic neuropathy: pain management considerations. Pain Clinic 2001; 3:11-16.
78. Milleret R. Cryoanalgesia of the nerves of the feet in distal arteritis in the elderly. J Mal Vasc 1983; 8:307-310.

79. Noback CR. Personal Communication. 